\begin{tabular}{|l|l|}
\hline Postprint Version & 1.0 \\
\hline Journal website & $\underline{\text { http://onlinelibrary.wiley.com/doi/10.1002/pon.1997/abstract }}$ \\
\hline Pubmed link & $\underline{\text { http://www.ncbi.nlm.nih.gov/pubmed/21671305 }}$ \\
\hline DOI & $10.1002 /$ pon.1997 \\
\hline
\end{tabular}

This is a NIVEL certified Post Print, more info at http://www.nivel.eu

\title{
Chemotherapy and information-seeking behaviour: characteristics of patients using mass-media information
} sources

\author{
LindA D. MUUSSES ${ }^{1,2, *}$, JULIA C.M. VAN WEERT ${ }^{1}$, SANDRA VAN DULMEN ${ }^{3}$, JESSE JANSEN ${ }^{4,5}$
}

Objective: Fulfilling patients' information needs can help them cope with illness and improve their well-being. Little research has been conducted on the characteristics of patients using different information sources. This study aims to get insight into which information sources patients receiving chemotherapy for the first time use and which factors (background characteristics, psychological factors, information needs and source reliability) explain the use of different mass-media information sources.

Methods: Three hundred forty-five patients receiving chemotherapy in ten hospitals in the Netherlands completed a questionnaire. Use of 16 sources (mass-media and interpersonal) was measured with a five-point Likert scale. Regression analyses were conducted to test whether use of the three most frequently used mass-media sources could be explained by sociodemographic, medical and psychological factors, unfulfilled information needs and perceived reliability of the source.

Results: Treatment guide, brochures and Internet were the most frequently used mass-media sources. Medical specialists, nurses, and family and/or friends were the most common interpersonal sources. Using the treatment guide was found to be associated with treatment goal, unfulfilled information needs and source reliability. Using brochures was associated with cancer-related stress responses, coping style and source reliability. Using Internet was associated with age, education, coping style and source reliability.

Conclusions: This study developed a model to explain the use of mass-media information sources by patients with cancer receiving chemotherapy. The use of different information sources is associated with different factors, indicating that each source offers specific opportunities to tailor information to the patient's needs.

\section{INTRODUCTION}

Undergoing chemotherapy (CT) is a stressful life experience [1]. Receiving appropriate information has been associated with better coping and improved well-being among patients with cancer [2,3]. However, patients often report dissatisfaction with the degree to which their information needs are met by their health care professionals $[3,4,5,6]$, and increasing number of patients are searching for health information from other sources, both interpersonal (e.g. pharmacist, family or friends) and mass media (e.g. brochures and the Internet) $[7,8]$. Seeking detailed information on cancer issues can help patients adjust to their situation [3] and can be part of their coping behaviour [9].

Although information-seeking behaviour in general has been studied before, as well as information sources used by patients with cancer, little research has attempted to explain the use of specific information sources. This study aims to gain insight into which factors motivate patients receiving CT treatment for the 
first time to seek information from different mass-media information sources. This is essential to better tailor information to the patient's needs, to enable patients to cope with their illness and to ensure high quality care. We focus on mass-media information sources, because the most common interpersonal information sources, such as physician and cancer nurse, are routinely used by the majority of patients.

One of the most prominent models in information-seeking behaviour is that designed by Wilson [10]. This interdisciplinary model describes how people seek and make use of information, the channels they employ to gain access to information and the factors that inhibit or encourage information use. The model can be applied to the information-seeking behaviour of patients with cancer and forms the basis of the conceptual model for this study.

\section{INFORMATION NEEDS}

Wilson [10] considers information needs to be the foundation of information-seeking behaviour. An information need is 'a recognition that your knowledge is inadequate to satisfy a certain goal that you have' [11] (p. 5). Patients with cancer are recognised as having specific information needs $[4,12,13]$ : cognitive information needs for factual information and knowledge about the illness and treatment (i.e. information about treatment, prognosis and rehabilitation); and affective communication and information needs so that they feel emotionally supported, accepted and reassured, and so that they feel free to discuss their concerns $[10,13,14]$. These needs lead to information goal setting, or motive, and may ultimately lead patients with cancer to use different information sources [15]. Subsequently, the uses and gratification theory assumes that people seek to gratify their complex needs through the use of various media [16].

\section{PSYCHOLOGICAL FACTORS}

Information-seeking behaviour cannot solely be explained by needs but also by the level of perceived stress and, consequently, the coping strategies that patients use [10]. Dealing with cancer places great psychological burdens on patients. Intrusive thoughts are thoughts that return, even though the person prefers not to think about the topic (at that time) [17]. Being diagnosed with cancer and the prospect of receiving severe treatments such as $\mathrm{CT}$ are distressing and might lead patients to have episodes of intrusive thinking about their illness, or to avoid thinking about their disease $[17,18]$.

Coping mechanisms and behavioural means that help to handle emotions or distress, and to manage the problem that is causing the distress are cognitive [19]. Information-seeking is considered a coping mechanism [20], although not for all patients [21, 22]. Miller and Mangan [23] use the terms monitoring and blunting for two counterpart information-based coping styles. Case et al.[9] found that about two-thirds of patients are monitors and one-third are blunters. Monitors prefer high information input regarding the stressful event and suffer less psycho-physiological arousal when they receive information, whereas blunters cope by setting aside their concerns and ignoring stress [20,24]. Generally, those with a monitoring style tend to require more information, and those with a blunting style feel better with less information [21].

Differences in information preferences can partly be explained by the fact that paying attention to information can cause mental discomfort: Information can be either a risk (the patient losing hope) or a reward (giving the patient a way of coping by providing the sense of knowing what is to come or what the options are) [25, 26]. Jenkins et al.[27] found that $87 \%$ of the patients with cancer they surveyed wanted all possible information, both good and bad news, whereas $13 \%$ preferred to leave disclosure decisions up to the doctor. Leydon et al. [26] reported that in particular 'unsafe' information was avoided (information that was either too detailed or could lead to losing hope). Information preferences are considered to affect information seeking both directly and through information needs [20,21]. For example, if one prefers not to get any bad news, certain information searches might violate that and indicate danger. It is generally accepted that the psychological factors described earlier (cancer-related stress reactions, coping style and information preferences) affect both information needs and information seeking [20,21]. To our knowledge, however, no research has been conducted on how these factors influence the use of specific information sources. Some sources might be expected to contain more 'dangerous' information than others (although there is disagreement about which these are; e.g. [15, 28]). It is, therefore, proposed that different psychological factors will explain the use of different sources. 


\section{PERSONAL FACTORS}

According to Wilson [10], personal factors such as socio-demographic characteristics might also affect information-seeking behaviour. Information seeking can be explained by age, gender and education. These socio-demographic factors are important in explaining information needs and source use [for a discussion, see $[1,27,29,30]]$.

In addition, some medical factors that are specific to patients with cancer have been confirmed to influence information-seeking behaviour. Patients with cancer do not just undergo one traumatic event; they go through different phases of their illness and treatment. Disease phase is considered to influence the information needs of patients with cancer and their use of information sources [12,28]. The current research focuses on patients with cancer who are receiving CT. Chemotherapy can be administered with either a palliative or a curative treatment goal. Curative treatment aims to cure the disease, whereas palliative treatment concentrates on reducing the severity of disease symptoms. The latter can be administered to relieve suffering and to improve quality of life [31]. Both treatment goal and quality of life are expected to influence the need for information and the sources used [32].

\section{INFORMATION SOURCES}

Wilson [10] predicted that the channel through which information is presented and the perceived credibility of the source affect information-seeking behaviour. We therefore study information-seeking behaviour as a behaviour expressed through the use of different information sources. A substantial body of research has investigated how different information sources are used by patients with cancer, including the mass media information sources that are increasingly being employed to provide information patients with cancer do not receive from their health care professionals $[7,8]$. Several studies have found that patients are most likely to use health care professionals, medical pamphlets, and family and friends as sources for cancer information. Newspapers, magazines, television and radio are also significant sources $[1,2,8,33$, $34,35]$. Studies have reported widely differing results for the use of Internet as a mass-media information source (i.e. websites) by patients with cancer, with results ranging from 4.0 to $41.5 \%$ [1, 2, 8, 33, 34, 35]. The highest percentage (41.5\%) was found in a study among women with breast cancer [33]. These percentages have presumably increased, because the majority of these studies are more than 5 years old, and Internet use to acquire medical information has increased rapidly during the past decade [36].

The characteristic of information sources that has been investigated most often is their perceived quality or reliability. Reliability is directly related to the use of the information source. Patients with cancer who did not use a particular source were found to have significantly lower trust in the source than groups who did use it [37]. The perceived reliability of the source is thus directly associated with the source a patient uses to seek information.

\section{PRESENT RESEARCH}

Based on the available research, we have developed a conceptual model for information-source use in patients with cancer new to CT; this model will be tested here (Figure 1). The objective of this study is to find out which information sources patients receiving CT for the first time use, and to examine which factors explain the use of the most frequently used mass-media sources.

\section{[FIGURE 1]}

\section{METHOD}

\section{Procedure}

Students of the University of Amsterdam were instructed to identify, in collaboration with a contact nurse, the 60 most recent oncology patients to start CT for the first time at each of the 10 different hospitals in the Netherlands. Patients were included if they were 18 years or older and were able to read Dutch. The questionnaire was sent to the addresses in the hospitals' medical files. The study was part of a larger research project on communication by the hospital preceding CT [38]. The study was approved by the Medical Ethical Committee of the University Medical Centre Utrecht, and local feasibility statements from all participating hospitals were received. 
In the Netherlands, patient education at the beginning of CT is generally provided by specialized oncology nurses. During a consultation of approximately $1 \mathrm{~h}$, the patient is provided with information about the treatment, side effects and how to deal with these side effects. To explain issues concerning CT treatment, a booklet 'Chemotherapy Treatment Guide (CT treatment guide)' is often used during these consultations. This booklet contains an overview of the most important treatment issues and is given to patients after (or sometimes before) the consultation. The consultation usually takes place between 2 weeks to 1 day before the first CT treatment [39]. In this study, all participants attended this consultation, and the consultation was marked as the 'start of CT'.

\section{MEASURES}

\section{Background variables}

Socio-demographic and medical background variables were obtained using a self-administered questionnaire containing items on age, gender, education and the goal of CT. Education was divided in three categories: low (primary education, lower vocational education), middle (senior secondary vocational education, university preparatory vocational education) and high (higher vocational education and university). Additionally, medical information (e.g. diagnosis, goal of CT) was obtained from hospital records.

\section{Quality of life}

To assess quality of life, the subscale 'Quality of life' of the EORTC QLQ-C30 was used [40]. The scale consists of two items measuring general health experience and quality of life, rated on a seven-point Likert scale $(1=$ very bad to $7=$ excellent $)$. Internal consistency was satisfactory $(r=0.828, p<0.001)$.

\section{Unfulfilled information needs}

Unfulfilled information needs at the start of CT were measured using the QUOTEchemo performance questionnaire. The QUOTEchemo performance questionnaire consists of 67 items asking patients whether they would have wanted the cancer nurse to pay more attention to specific information and communication themes at the beginning of CT, measured on dichotomous response categories ('yes', 'no'). Unfulfilled information need scales were calculated for three cancer-specific dimensions, namely treatment-related information (20 items, $\alpha=0.92$ ), prognosis information (three items, $\alpha=0.68$ ), and rehabilitation information (11 items, $\alpha=0.87$ ) and four general dimensions, namely coping information (seven items, $\alpha=$ 0.79 ), interpersonal communication (six items; $\alpha=0.88$ ), tailored communication ( 10 items, $\alpha=0.85$ ), and affective communication ( 10 items, $\alpha=0.89$ ). Psychometric properties were satisfactory to good. The development of the QUOTEchemo questionnaire has been extensively described [13].

\section{Cancer-related stress reactions}

The Dutch version of the Impact of Events Scale [41, 42], measuring a subscale of intrusion (seven items, $\alpha=0.85$ ) and a subscale of avoidance of cancer-related stressful thoughts (eight items, $\alpha=0.79$ ), was administered. Participants rated the frequency of intrusive and avoidance cognitions on a four-point Likert scale $(0=$ 'not at all', $1=$ 'rarely', $3=$ 'sometimes', $5=$ 'often'). Total intrusion and avoidance scores were rated (range 0-35 and 0-40, respectively) in the context of the stressful experience of being treated for cancer.

\section{Coping style}

A three item five-point Likert scale questionnaire was used to measure monitoring coping style. This questionnaire was derived from the Threatening Medical Situation Inventory [43, 44]. Statements about patients monitoring intentions to: (1) respond to the situation by reading about cancer; (2) going as deeply as possible into information on treatment; and (2) getting information from the medical specialist before $\mathrm{CT}$, could be rated from 1 (not at all applicable to me) to 5 (strongly applicable to me). Total monitoring scores were calculated as the total scores on the items (range 3-15, Cronbach's $\alpha=0.78$ ).

\section{Information preference}

The questionnaire assessed information preference by using an adapted item of the Information Satisfaction Questionnaire [45], measuring whether patients: (1) wanted as much information as possible, both positive and negative; (2) wanted as much information possible, both positive and negative, but bit by bit; (3) did not want too much information; or (4) only wanted positive information. The scores had a 
skewed distribution ( $5 \%$ did not need much information, and $10 \%$ only wanted positive information). To resolve this, the items were recoded with (1) and (2) combined into 'wants as much information as possible' and (3) and (4) into 'does not want as much information as possible'.

\section{Information source use and reliability}

Based on literature search, nine interpersonal and seven mass media sources were chosen $[1,34]$. Interpersonal sources were the cancer specialist, oncology nurse, general practitioner, practitioner of alternative medicine, second opinion specialist, pharmacist, family/friends, patient association and other patients. Mass media sources were the CT treatment guide, other brochures, magazines, newspapers, books, Internet and TV/radio. Respondents were asked to rate how often they used the 16 different information sources for information about CT on a five-point Likert scale, ranging from 1 (did not use) to 5 (used often). To display percentages of use, the categories little and sometimes ( 2 and 3 ) were combined to form ' $\leq$ sometimes', regularly and often (4 and 5) were taken together to form ' $\geq$ regularly' and never (1) was left to represent never. Respondents were asked to rate the reliability of the information sources according to how useful and responsible the patients found their information about CT. Source reliability was measured on a five-point Likert scale ranging from 1 (very unreliable) to 5 (very reliable).

\section{DATA ANALYSIS}

Missing values on items that were part of the unfulfilled information needs scales were replaced according to the 'mean value of valid sub-test principle': the mean of the completed items within the subscale for a particular participant was substituted when more than $25 \%$ were completed [46].

Separate linear regression analyses were conducted with the mass-media information sources that more than $25 \%$ of the patients used regularly or often by as dependent variables. The following four sets of independent variables were entered as separate blocks: (1) background characteristics; (2) psychological factors; (3) information needs; and (4) source reliability.

All analyses were performed using SPSS 17.0 (IBM Corporation, Somers, NY, USA). Significance levels were set at $\alpha=0.05$.

\section{RESULTS}

\section{Response}

Initially, 606 patients were selected. However, nine of these patients had already participated in a parallel study and were therefore excluded. Of the remaining 597patients, nine had passed away, three had moved to an unknown address and three said they had not received CT. This meant that we contacted 582 subjects, of whom $345(59.3 \%)$ returned the questionnaire. A non-response analyses revealed there was no difference in gender $(\chi 2(1)<0.001, \mathrm{p}=0.988)$, age $(\mathrm{t}(579)=0.362, \mathrm{p}=0.717)$ and diagnosis $(\chi 2(7)=5.034, \mathrm{p}=$ $0.656)$ between patients who responded and patients who did not respond.

\section{Participants}

Table 1 presents background information about the respondents. Educational level was divided into lower, middle and higher. Almost half the respondents had a lower educational level (47.2\%), more than twothirds of the respondents was female $(67.0 \%)$, and the treatment intent was curative for almost threequarters of the respondents according to hospital records (74.8\%).

\section{[TABLE 1]}

\section{Use of sources}

The use of the nine interpersonal sources and seven mass media sources were surveyed. Figures 2 and 3 display the use of these sources in percentages. Interpersonal information sources, including cancer specialists, oncology nurses, family and friends were used regularly or often by more than $25 \%$ of patients (ranging from 30.1 to $63.2 \%$ ). For mass media information sources, the CT treatment guide, brochures and the Internet were used regularly or often by more than $25 \%$ of patients (ranging from 27.6 to $45.3 \%$ ). These three mass media information sources were used as dependent variables in the analysis, as explained in the previous section. 


\section{[FIGURE 1 AND FIGURE 2]}

\section{Explaining source use}

Multivariate regression analyses were used to test the association of the background characteristics, psychological factors, unfulfilled information needs and source reliability with information source use. Table 2 shows the coefficients and their significance levels. Perceived source reliability is associated with information source use: Higher perceived reliability of a source is associated with higher use of that source. Using Internet is negatively related with age and positively related to a middle and high educational level and monitoring, which indicates that people who are younger, higher educated and have a higher need for information-seeking are more likely to use Internet. Use of the CT treatment guide is negatively related to unfulfilled interpersonal communication needs and positively related to a curative treatment goal and unfulfilled information needs related to the treatment and prognosis. This indicates that higher educated patients, patients receiving curative $\mathrm{CT}$ and patients who are dissatisfied with the provision of information about treatment and prognosis during the consultation are more likely to use the CT treatment guide as an additional information source, whereas patients who are dissatisfied with the provision of interpersonal communication are less likely to use it. Using brochures is negatively associated with avoidance and positively associated with intrusion and monitoring. This indicates that patients who have avoidant styles are less likely to use brochures, whereas patients who suffer from intrusive thoughts and have a monitoring coping style are more likely to use them.

\section{[TABLE 2]}

\section{DISCUSSION}

This study provides further evidence that patients do not rely exclusively on their health care providers for information. Mass-media information sources such as Internet (27.6\%), the CT treatment guide (45.8\%) and additional brochures $(30.1 \%)$ are used regularly or often by between a quarter and almost half of the patients. These numbers demonstrate the importance of understanding which factors explain mass media information source use among patients with cancer.

One of the clearest associations with the use of an information source is its perceived reliability. An increase in source reliability concurs with large increases in the use of that source. This is true for all researched sources. Previous research among patients with cancer has also found a relationship between source use and trust in that source [37]. Especially with Internet use, reliability has been identified as a problem. Many studies have reported that information about cancer is often of poor quality, and patients lack the tools to evaluate information quality $[47,48]$. This might account for the low trust in the reliability of websites [49]`. Internet sites, compared with the CT treatment guide and brochures, are much more open to poor quality information, and it is especially difficult to assess the source of the information on the Internet $[47,50]$. However, other research has found that when asked to list their favourite health information websites, women with breast cancer listed mostly websites from objectively reliable sources [51]. An advantage of the Internet is the opportunity to easily tailor information to the patient's specific needs and situation. Web-based tailored information is not only increasingly being used in health care, especially for health education, but also for patient information $[52,53]$. Tailored websites are perceived by patients as more reliable than regular websites [49] and have the potential to transform the patientphysician relationship from that of physician authority dictating advice and treatment to that of informed decision making between patient and physician [54]. Tailored or personally relevant information has been found to be processed more deeply and is therefore likely to improve comprehension and recall of information [55]. This might ultimately contribute positively to treatment compliance, patient satisfaction, health and well-being [56]. Based on our findings, we cannot make any conclusions about what the best source of information is for CT patients. However, our findings show that the information source used was clearly associated with perceived reliability. An obvious recommendation would be for a health provider to provide the patient with (a list of) reliable Internet websites and brochures.

The patients surveyed in this study were informed about CT through a meeting with the cancer nurse. Unfulfilled information needs after this meeting can explain the use of the CT treatment guide. In the meeting, patients were given information, which referred to the treatment guide. If the need for information about the treatment and prognosis was not met, patients used the treatment guide to fulfil these unmet needs 
afterwards. We can conclude that unmet information needs seem to lead to information seeking from a related, additional information source. On the other hand, patients who experienced a lack of interpersonal communication from the cancer nurse used the treatment guide less often. The treatment guide provides practical and CT-specific information, and presumably does not satisfy the need for interpersonal communication as well as interpersonal information sources could.

Being diagnosed with cancer and the prospect of getting treatments such as CT are distressing situations and might lead to episodes of intrusive thinking about the illness and avoiding thinking about the disease $[17,18]$. The effect of these stress reactions on information seeking has, to our knowledge, not been studied yet. In this study, intrusive thoughts and avoidance are associated with the use of brochures. More intrusive thoughts were associated with more use of the brochure, whereas more avoidance was associated with less use. The direction of the results seems straightforward. When a patient suffers from intrusive thoughts, many questions may come up, leading to more information seeking. A patient who avoids thinking about his or her situation as a response to the stress will prefer not to be confronted with the topic, so he or she will not use information seeking as a way of coping. The question that remains is why the use of brochures is explained by cancer-related stress responses, but not Internet use. This could be because brochures are often provided by the hospital, together with the $\mathrm{CT}$ treatment guide, whereas Internet sites have not generally been recommended. Internet use therefore requires more pro-active behaviour on the part of patients. However, this might change rapidly as more and more hospitals develop their own personalized websites for patients. In order to better understand health information seeking on the Internet, this relationship should be further investigated.

Coping style affects the information seeking of patients with cancer, both in the case of brochures and the Internet. Patients with a monitoring coping style prefer a high information input and suffer less psychophysiological arousal when they receive information [20,24]. Brochures and the Internet could provide monitors the desired level of information, which can enable them to manage the problem that is causing the distress [19], in this case cancer and CT. No significant relation was found for the treatment guide. This can be explained by its content, and the fact that the treatment guide was more integrated in healthcare than the other mass-media information sources: No predisposition towards information seeking was necessary to acquire the guide. In addition, the guide's practical nature makes it a vital source for need-to-know information on $\mathrm{CT}$.

The treatment goal of $\mathrm{CT}$ was predicted to be related to information seeking. It was assumed that patients receiving palliative treatment will generally be less interested in detailed information [31,32]. In this study, patients receiving curative $\mathrm{CT}$ were indeed more likely to use the treatment guide than patients receiving palliative treatment. This suggests that patients with more chance of a cure want more concrete information than those with less chance.

As predicted, level of education does have an effect on information seeking. In the literature, patients with a higher educational level have been found to seek more information than those with a lower educational level $[12,37]$, and higher educated patients seek information from a wider range of sources than lower educated ones[1, 12]. In particular, the use of the Internet was hypothesized to be influenced by education $[8,33,35,37]$. Results do indeed show that patients with a high or middle educational level use the Internet more often than patients with a lower educational level. Similar results were not found for the treatment guide and the brochures. One possible explanation could be that the treatment guide and the brochures are provided by the hospital and are usually recommended by the cancer nurse.

Lastly, it was hypothesised that younger patients would use the Internet more often than older patients [8, $33,35]$. This relation was also confirmed in the present study. This relation is likely to change in the coming years, because this is most likely a cohort (or generation) effect than an age effect [57].

One of the limitations of this research is the accuracy of the measures of source use and unfulfilled information needs. Patients were asked to judge retrospectively how often they had used the information sources, and what information needs had not been fulfilled in the meeting with the cancer nurse. A more accurate measure would, for instance, have been if they had kept a diary of their source use and information needs. However, this would have been an intrusion in the patient's life, and might thus have reduced the number of respondents.

Moreover, although the proportion of explained variance is satisfactory, the proposed model does not explain all of the variance in use of the information sources. This means that one should still be looking for alternative variables to explain the use of information sources. 


\section{CONCLUSION}

This study has found models to explain the use of mass media information sources by patients with cancer receiving CT for the first time. We argued that different sources are used by different people: in other words, that the use of the three different information sources is best explained by other groups of variables. Each information source seems to attract its own 'audience'.

The results of this study aid the understanding of the use of mass media by patients with cancer, at a time when mass media are increasingly being used to provide health information. The specific findings can be used to further aid patients to use information in coping with cancer and the treatment thereof, for example by tailoring information to the patient's needs using specific media to address specific patients and their needs.

\section{ACKNOWLEDGEMENTS}

We thank all the participants who were willing to complete an extensive questionnaire during a difficult period of their life. Furthermore, we thank the students of the Department of Communication Science of the University of Amsterdam for their help in data gathering and data entry. We gratefully acknowledge the Dutch Cancer Society (grant number NIVEL 2003-2973) and the Amsterdam School of Communication Research/ASCoR for funding this study.

Conflict of interest statement: None declared.

\section{REFERENCES}

1 Ankem K. Use of information sources by cancer patients: results of a systematic review of the research literature. Inf Res 2006;11:254. doi: http://informationr.net.proxy.library.uu.nl/ir/113/paper254.htmIUBULINK

2 Mills ME, Davidson R. Cancer patients' sources of information: use and quality issues. Psycho-Oncology 2002;11:371-378. doi: 10.1002/pon.584

3 Arora NK, Johnson P, Gustafson DH, McTavish F, Hawkins RP, Pingree S. Barriers to information access, perceived health competence, and psychosocial health outcomes: test of a mediation model in a breast cancer sample. Patient Educ Couns 2002;47:37-46. doi: 10.1016/S0738-3991(01)00170-7

4 Hack TF, Degner LF, Parker PA. The communication goals and needs of cancer patients: a review. Psycho-Oncology 2005;14:831-845. doi: 10.1002/pon.949

5 Echlin KN, Rees CE. Information needs and information seeking behaviours of men with prostate cancer and their partners: a review of the literature. Cancer Nurs 2002;25:35-41. doi: 35400010013010.0050

6 James C, James N, Davies D, Harvey P, Tweddle S. Preferences for different sources of information about cancer. Patient Educ Couns 1999;37:273-282. doi: 10.1016/S0738-3991(99)00031-2

7 Cline RJW, Haynes KM. Consumer health information seeking on the internet: the state of the art. Health Educ Res 2001;16:671-693. doi: 10.1093/her/16.6.671

8 Carlsson M. Cancer patients seeking information from sources outside the health care system. Support Care Cancer 2000;8:453-457. doi: 10.1007/s005200000166

9 Case DO, Andrews JE, Johnson JD, Allard SL. Avoiding versus seeking: the relationship of information seeking to avoidance, blunting, coping, dissonance, and related concepts. J Med Libr Assoc 2005;93:353-362. doi: 35400013795308.0050

10 Wilson TD. Information behaviour: an interdisciplinary perspective. Inf Process Manage 1997;33:551572. doi: 10.1016/S0306-4573(97)00028-9

11 Case DO. Looking for Information-A Survey of Research on Information Seeking, Needs, and Behaviour. Academic Press: San Diego, 2002

12 Rutten LJF, Arora NK, Bakos AD, Aziz N, Rowland J. Information needs and sources of information among cancer patients: a systematic review of research. Patient Educ Couns 2005;57:250-261. doi: 10.1016/j.pec.2004.06.006

13 Van Weert JCM, Jansen J, de Bruijn GJ, Noordman J, van Dulmen S, Bensing JM. QUOTEchemo: a patient-centered instrument to measure quality of communication preceding chemotherapy treatment through the patient's eyes. Eur J Cancer Care 2009;45:2967-2976. doi: 10.1016/j.ejca.2009.06.001

14 Bensin JM. Doctor-Patient Communication and the Quality of Care. NIVEL: Utrecht, 1991.

15 Hardyman R, Hardy P, Brodie J, Stephens R. It's good to talk: comparison of a telephone helpline and website for cancer information. Patient Educ Couns 2005;57:315-320. doi: 10.1016/j.pec.2004.08.009

16 Fiske J. Introduction to Communication Studies (2nd edn). Routledge: London, 1990

17 Horowitz M, Wilner N, Alvarez W. Impact of event scale: a measure of subjective stress. Psychosom Med 1979;41:209-218. doi: 0033-3174/79/03020910/\$0l .75 
18 Ong LML, Visser MRM, Van Zuuren FJ, Rietbroek RC, Lammes FB, De Haes JCJM. Cancer patients' coping styles and doctor-patient communication. Psycho-Oncology 1999;8:155-166. doi:

10.1002/(SICl)1099-1611(199903/04)8:2<155::AID-PON350>3.0.CO;2-A

19 Folkman S. Personal control and stress and coping processes: a theoretical analysis. J Pers Soc

Psychol 1984;46:839-852. doi: 10.1037/0022-3514.46.4.839

20 Miller SM. Monitoring versus blunting styles of coping with cancer influence the information patients want and need about their disease. Cancer Nurs 1995;76:167-177. doi: 10.1002/1097-

0142(19950715)76:2<167::AID-CNCR2820760203>3.0.CO;2-K

21 Lenz ER. Information seeking: a component of client decisions and health behaviour. Adv Nurs Sci 1984;6:59-72.

22 Derdiarian A. Informational needs of recently diagnosed cancer patients. A theoretical framework.

Cancer Nurs 1987;10:107-115.

23 Miller SM, Mangan CE. Interacting effects of information and coping style in adapting to gynaecological stress: should a doctor tell all? J Pers Soc Psychol 1983;45:223-236. doi: 10.1037/0022-3514.45.1.223

24 Timmermans LM, van Zuuren FJ, van der Maazen RWM, Leer JWH, Kraaimaat FW. Monitoring and blunting in palliative and curative radiotherapy consultations. Psycho-Oncology 2007;16:1111-1120. doi: 10.1002/pon.1177

25 Thorne S, Hislop TG, Kuo M, Armstrong EA. Hope and probability: patient perspectives of the numerical information in cancer communication. Qual Health Res 2006;16:318-336. doi:

$10.1177 / 1049732305285341$

26 Leydon GM, Boulton M, Moynihan C, et al. Cancer patients' information needs and information seeking behaviour: in depth interview study. Br Med J 2000;320:909-913. doi: 10.1136/bmj.320.7239.909

27 Jenkins V, Fallowfield L, Saul J. Information needs of patients with cancer: results from a large study in UK cancer centres. Br J Canc 2001;84:48-51. doi: 10.1054/bjoc.2000.1573

28 Squiers L, Rutten LJF, Treiman K, Bright MA, Hesse B. Cancer patients' information needs across the cancer care continuum: evidence from the cancer information service. J Health Inf 2005;10:15-34. doi: $10.1080 / 10810730500263620$

29 Galloway S, Graydon J, Harrison D, et al. Informational needs of women with a recent diagnosis of breast cancer: development and initial testing of a tool. J Adv Nurs 1997;25:1175-1183. doi: 10.1046/j.1365-2648.1997.19970251175.x

30 Giacalone A, Blandino M, Talamini R, et al.. What elderly cancer patients want to know? Differences among elderly and young patients. Psycho-Oncology 2007;16:365-370. doi: 10.1002/pon.1065

31 BradyLW, HeilmannHP, MollsM Introduction In Palliative Radiation Oncology (Vol. 1-2). Springer: New York, 2003.

32 Van Koerten C, Feytens M, Jansen J, Van Dulmen S, Van Weert JCM. Communication needs of cancer patients cancer preceding chemotherapy: a study into the role of curative or palliative treatment goal, age and gender, in press.

33 Fogel J, Albert SM, Schnabel F, Ditkoff BA, Neugut Al. Use of the Internet by women with breast cancer. J Med Internet Res 2002;4, Published Online. doi: http://hdl.handle.net/1807/4642

34 Raupach JCA, Hiller JE. Information and support for women following the primary treatment of breast cancer. Health Expect 2002;5:289-301. doi: 10.1046/j.1369-6513.2002.00191.x

35 Helft PR, Eckles RE, Johnson-Calley CS, Daugherty CK. Use of Internet to obtain cancer information among cancer patients at an urban country hospital. J Clin Oncol 2005;23:4954-4962. doi: $10.1200 / J C 0.2005 .09 .621$

$36 \mathrm{Hu}$ Y, Sundar SS. Effects of online health sources on credibility and behavioural intentions. Communic Res 2010;37:105-132. doi: 10.1177/0093650209351512

37 Mayer DK, Terrin NC, Kreps GL, et al.. Cancer survivors information seeking behaviors: a comparison of survivors who do and do not seek information about cancer. Patient Educ Couns 2007;65:342-350. doi: 10.1016/j.pec.2006.08.015

38 Van Weert JCM, Jansen J, Spreeuwenberg PMM, Van Dulmen S, Bensing JM. Effects of communication skills training and a question prompt sheet to improve communication with older cancer patients: a randomized controlled trial. Crit Rev Oncol Hematol, in press.

39 Posma ER, van Weert JCM, Jansen J, Bensing JM. Older cancer patients' information and support needs surrounding treatment: an evaluation through the eyes of patients, relatives and professionals. BMC Nurs 2009;8:1-15.

40 Aaronson NK, Ahmedzai S, Bergman B, et al.. The European organization for research and treatment of cancer QL-C30: a quality-of-life instrument for use in international clinical trials in oncology. J Natl Cancer Inst 1993;85:365-376. doi: 10.1093/jnci/85.5.365 
41 Pieterse A, Van Dulmen S, Ausems M, Schoemaker A, Beemer F, Bensing JM. QUOTE-geneca: development of a counselee-centered instrument to measure needs and preferences in genetic counseling for hereditary cancer. Psycho-Oncology 2005;14:361-375. doi: 10.1002/pon.853

42 Van der Ploeg E, Mooren TTM, Kleber RJ, Van der Velden PG, Brom D. Construct validation of the Dutch version of the impact of event scale. Psychol Assess 2004;16:16-26. doi: 10.1037/10403590.16.1.16

43 Miller SM. Monitoring and blunting: validation of a questionnaire to assess styles of information under threat. J Pers Soc Psychol 1987;52:345-353.

44 Van Zuren FJ, De Groot KI, Mulder NL, Muris P. Coping with medical threat: an evaluation of the Threatening Medical Situations Inventory (TMSI). Pers Individ Differ 1996;21:16-26. doi: 10.1016/01918869(96)00029-3UBULINK

45 Thomas R, Kaminski E, Stanton E, Williams M. Measuring information strategies in oncology. Developing an information satisfaction questionnaire. Eur J Cancer Care 2004;13:65-70. doi: 10.1111/j.1365-2354.2004.00445.x

46 Fairclough DL, Cella DF. Functional assessment of cancer therapy (FACT-G): non-response to individual questions. Qual Life Res 1996;5:321-329. doi: 10.1007/BF00433916

47 Jones J. Development of a self-assessment method for patients to evaluate health information on the Internet. Paper presented at the American Medical Informatics Association, 1999.

Jones J. Development of a self-assessment method for patients to evaluate health information on the Internet. Paper presented at the American Medical Informatics Association, 1999.

48 Jadad AR, Gagliardi A. Rating health information on the Internet: navigating to knowledge or to babel? J Am Med Assoc 1998;279:611-614. doi: 35400007835482.0080

49 Oenema A, Brug J, Lechner L. Web-based tailored nutrition education: results of a randomized controlled trial. Health Educ Res 2001;16:647-660. doi: 10.1093/her/16.6.647

50 Hoffman-Goetz L, Nancarrow Clarke J. Quality of breast cancer sites on the world wide web. Can J Public Health 2000;91:281-284. doi: 35400009139271.0090

51 Fogel J, Albert SM, Schnabel F, Ditkoff BA, Neugut Al. Quality of health information on the Internet. JAMA, J Am Med Assoc 2001;286:2093-2094. doi: 10.1001/jama.286.17.2092

52 Lustria MLA, Cortese J, Noar SM, Glueckauf RL. Computer-tailored health interventions delivered over the web: review and analysis of key components. Patient Educ Couns 2009;74:156-173. doi: 10.1016/j.pec.2008.08.023

53 Noar SM, Benac CN, Harris MS. Does tailoring matter? Meta-analytic review of tailored print health behavior change interventions. Psychol Bull 2007;133:673-693. doi: 10.1037/0033-2909.133.4.673

54 Winker MA, Flanagin A, Chi-Lum B, et al.. Guidelines for medical and health information sites on the internet: principles governing AMA web sites. J Am Med Assoc 2000;263:1600-1606. doi: 10.1001/jama.283.12.1600

55 Rimer BK, Kreuter MW. Advancing tailored health communication: a persuasion and message effects perspective. J Commun 2006;56:184-201. doi: 10.1111/j.1460-2466.2006.00289.x

56 De Vries M, Van Weert JCM, Jansen JVL, Maas H. Step by step development of a clinical pathway for older cancer patients. Eur J Cancer 2007;43:2170-2178. doi: 35400017350605.0040

57 Loos EF, Mante-Meijer EA. Navigatie van ouderen en jongeren in beeld. Explorerend onderzoek naar de rol van leeftijd voor het informatiezoekgedrag van websitegebruikers. [Navigation of Older and Younger People. Explorative Study Into the Role of Age on Website Users' Information Search Behavior]. Lemma: Den Haag, 2009. 
Muusses, L.D., Weert, J.C.M. van, Dulmen, S. van. Chemotherapy and information-seeking behaviour: characteristics of patients using mass-media information sources. Psycho-Oncology: 2012, 21(9), 993-1002

\section{TABLES AN DFIGURES}

Figure 1. Conceptual model of information source use by patients with cancer at the beginning of chemotherapy treatment

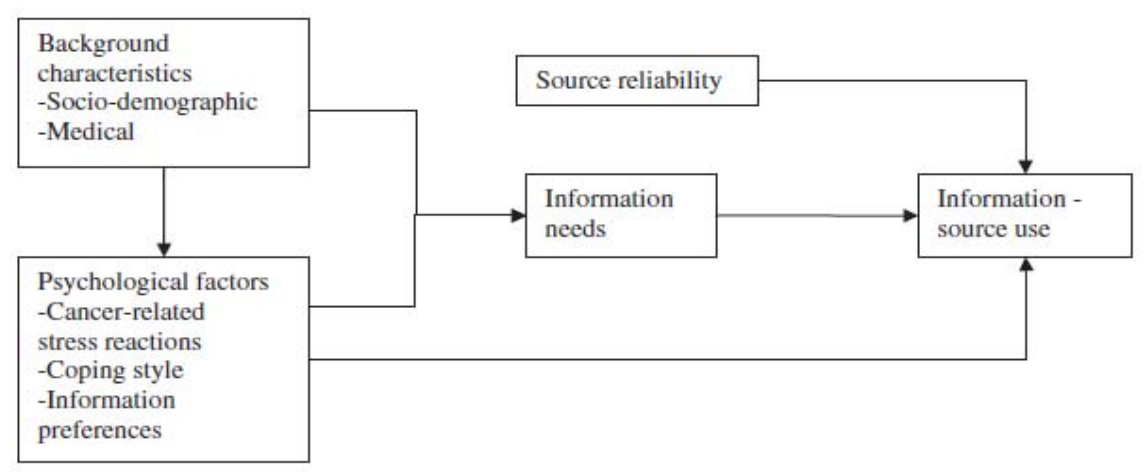


Muusses, L.D., Weert, J.C.M. van, Dulmen, S. van. Chemotherapy and information-seeking behaviour: characteristics of patients using mass-media information sources. Psycho-Oncology: 2012, 21(9), 993-1002

Table I. Background and medical information about the respondents $(N=345)$

\begin{tabular}{|c|c|c|}
\hline Characteristics & $\bar{N}$ & Percentage \\
\hline \multicolumn{3}{|l|}{ Gender } \\
\hline Female & 231 & 67.0 \\
\hline Male & 114 & 33.0 \\
\hline \multicolumn{3}{|l|}{ Age } \\
\hline Mean (SD) & $55.7(11.0)$ & \\
\hline Range & $20-84$ & \\
\hline \multicolumn{3}{|l|}{ Education level } \\
\hline Low & 162 & 47.2 \\
\hline Middle & 85 & 24.8 \\
\hline High & 96 & 28.0 \\
\hline \multicolumn{3}{|l|}{ Diagnosis } \\
\hline Breast cancer & 160 & 47.2 \\
\hline Lung tumour & 33 & 9.7 \\
\hline Gastro-enterological tumour & 73 & 21.5 \\
\hline Gynaecological tumour & 21 & 6.2 \\
\hline Hematological tumour & 36 & 10.6 \\
\hline Urological tumour & 10 & 2.9 \\
\hline Other & 6 & 1.8 \\
\hline \multicolumn{3}{|l|}{ Treatment intent (hospital) } \\
\hline Curative & 234 & 74.8 \\
\hline Palliative & 79 & 25.2 \\
\hline \multicolumn{3}{|l|}{ Infusion method chemotherapy } \\
\hline Intravenous & 266 & 78.0 \\
\hline Oral (pills) & 2 & 0.6 \\
\hline Combination & 73 & 21.4 \\
\hline \multicolumn{3}{|c|}{ How much do you suffer from side effects? } \\
\hline More than expected & 108 & 32.0 \\
\hline As much as expected & 78 & 23.0 \\
\hline Less than expected & 152 & 45.0 \\
\hline \multicolumn{3}{|c|}{ Treatments in addition to chemotherapy* } \\
\hline Only chemotherapy & 51 & 15 \\
\hline Operation & 254 & 74.5 \\
\hline Radiation & 155 & 45.5 \\
\hline Hormone treatment & 72 & 21.1 \\
\hline Immunotherapy & 21 & 6.2 \\
\hline
\end{tabular}

* Percentages do not add up to 100 because patients can have more than one additional treatment. 
Figure 2. Use of interpersonal information sources

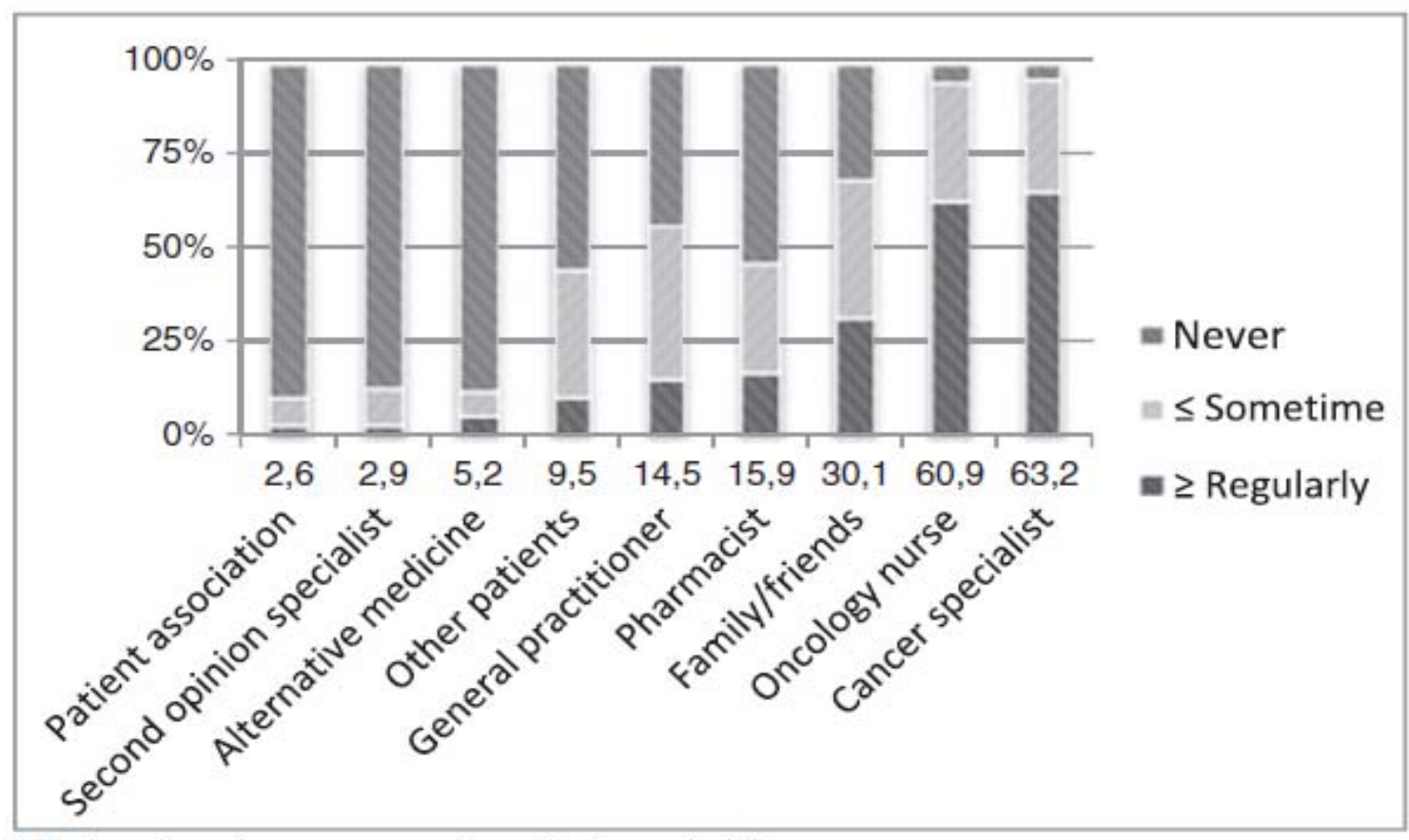

(displayed numbers are percentages for $\geq$ regularly)

Figure 3. Use of mass media information sources

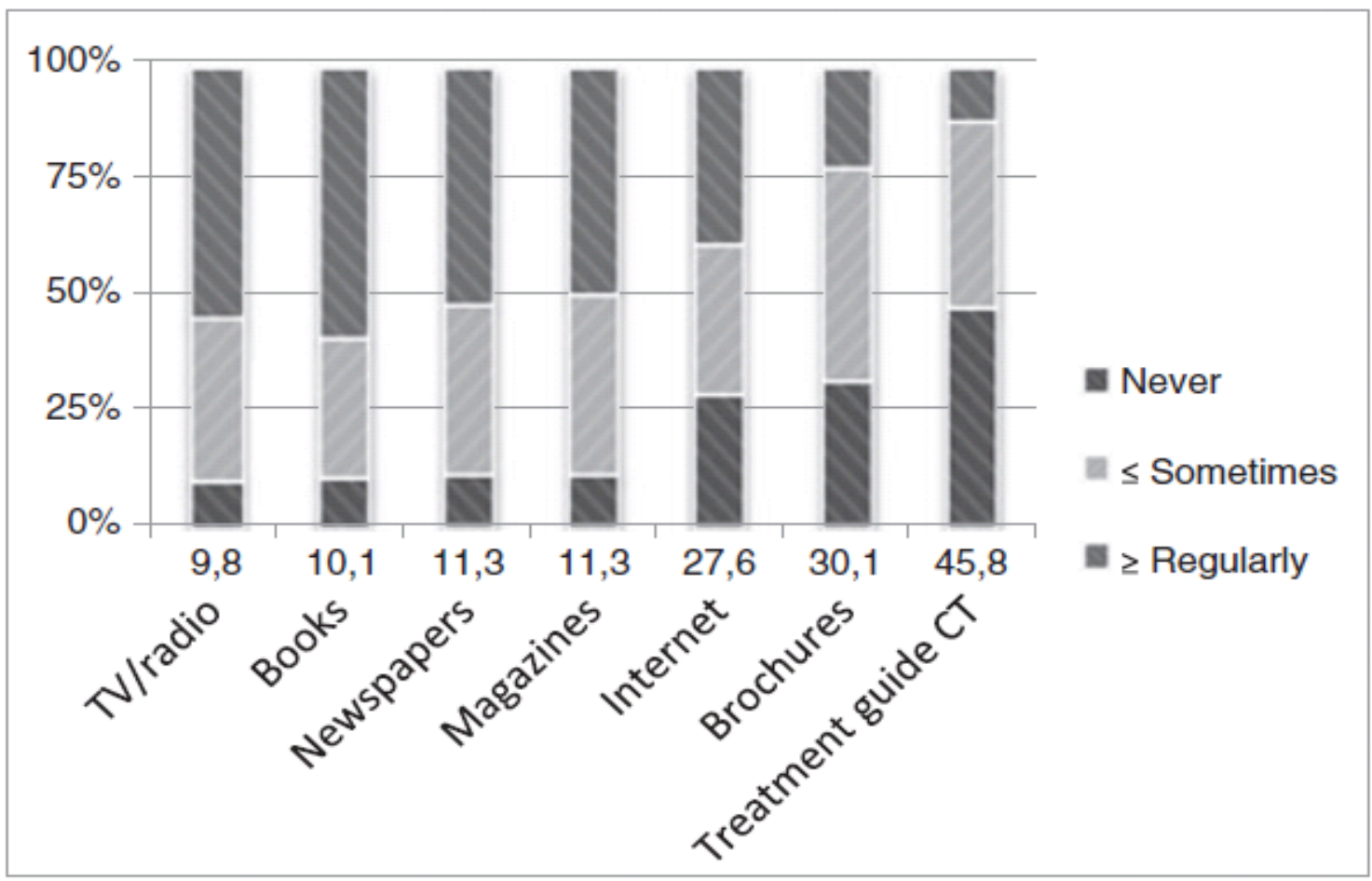

(displayed numbers are percentages for $\geq$ regularly) 


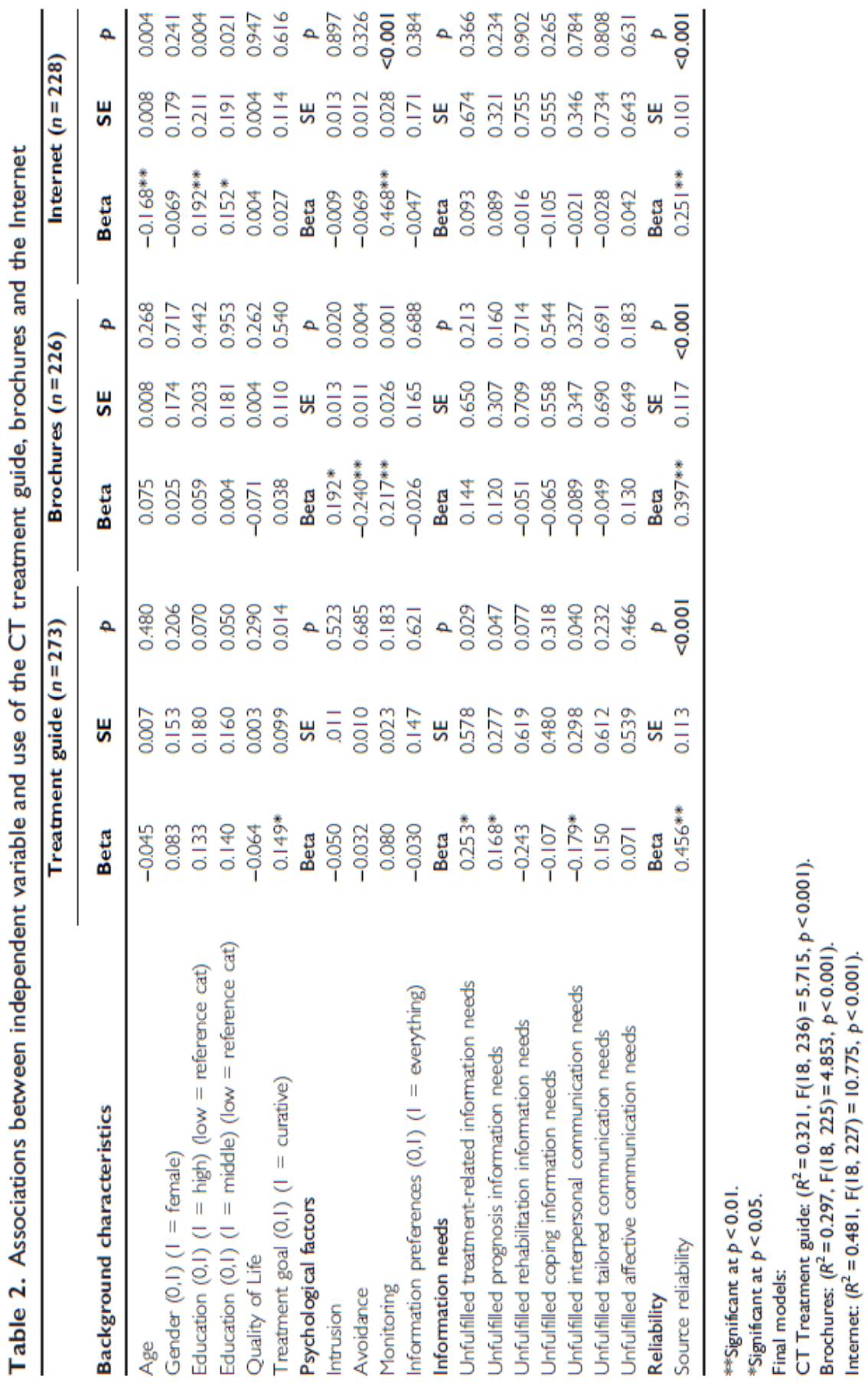

